\title{
Secondary User Relations in Emerging Mobile Computing Environments
}

\begin{abstract}
Mobile technologies are enabling access to information in diverse environments and are exposing a wider group of individuals to said technology. Therefore, this paper proposes that a wider view of user relations than is usually considered in information systems research is required. Specifically, we examine the potential effects of emerging mobile technologies on end user relations with a focus on the 'secondary user', those who are not intended to interact directly with the technology but are intended consumers of the technology's output. For illustration, we draw on a study of a UK regional Fire and Rescue Service and deconstruct mobile technology use at Fire Service incidents. Our findings provide insights which suggest that, because of the nature of mobile technologies and their context of use, secondary user relations in such emerging mobile environments are important and need further exploration.
\end{abstract}

\section{Introduction}

This paper proposes that as the mobility and ubiquity of computing increases so the number of people affected as a by-product may increase as a wider, more diverse set of users are exposed to the technology. Drawing on the work of Friedman and Cornford, (1989, p.185) and Eason, (1988, p.92) we revise their definitions of different user categories to reflect the integrated nature of modern information technology focussing on two categories of user - primary user and secondary user. For any given scenario:

Primary Users: those who are intended to interact directly with the technology, they input data, manipulate data and may consume the output;

Secondary Users: those who are not intended to interact directly with the technology but are intended consumers of the output. 
The fundamental difference between primary and secondary users is that, in a given scenario, the first category directly interact with a given technology whilst the second do not. Dependent on the scenario, a primary user may change into a secondary user (and vice versa). For example, a call centre worker is a primary user when using software to interact with a customer. They become a secondary user when faced with reports derived from their inputted data that have been created by their manager. Additionally, a call centre customer, if a recipient of data from the call centre software, also falls into the secondary user category. Within information systems, the literature on primary users is well-developed cf.(Flynn, 1998, Flynn and Davarpanah Jazi, 1998, Fitzgerald et al., 2002). Similarly, in the mobile computing field there have been numerous studies on primary users, for example on the actual mobility that mobile technologies allow (Dahlbom and Ljungberg, 1998), on interaction overload (Ljungberg and Sorensen, 2000) and on the erosion of control over the working environment (Kristoffersen and Ljungberg, 2000, Laurier, 2001).

In terms of secondary user considerations in information systems, since Eason's (1988) and Friedman and Cornford's (1989) early definitions of secondary users, attention to this group's interactions with primary users has been scant with the emphasis being on stakeholder dynamics rather than specifically on secondary users (Sharp et al., 1999, Pouloudi and Whitley, 1997, Hosein and Whitley, 2002, Checkland and Holwell, 1997). Considering secondary users and mobile technologies, there is recognition that the use of mobile technologies in 'the large' will mean that private activity will no longer necessarily take place discreetly, away from the public domain (Cooper, 2002). However, there is limited empirical work that puts secondary users centre stage. Luff and Heath's (1998) key work into the study of 'local' or 'micro' mobility does 
highlight mobile technologies as potentially inhibiting interaction between healthcare professionals and patients and similarly, Weilenmann and Larsson (2002) in their observations on teenagers' collaborative construction of text messages, illustrate how secondary users can become 'collective' primary users. However, these studies have not focussed on how the mobility of technology can influence the dynamics in the relationships between primary and secondary users; it is this issue that we aim to make a modest contribution towards. To investigate this, we draw upon a case study concerning the implementation and use of mobile ICTs in a UK Fire and Rescue Service.

In the next section we provide an overview of our approach to data collection and analysis. Following this, an interpretation and discussion of the data is presented. We close with the conclusions from the study, its implications, and some recommendations for future research.

\section{Research Methodology}

To study the dynamics between primary and secondary users in a mobile context, we employed a case study approach examining the use of a range of mobile technologies in a UK regional Fire Service. Our approach was to explore cases which offered rich insight into mobile technology use via focus group based story telling (Miles and Huberman, 1994, Walsham, 1995, Yin, 1994, Snowden, 2002, Gabriel, 2000). Guided by Myers (1997) assertion that interpretive research should present the multiple viewpoints of those involved and their different problems, a number of people contributed to the stories, stories were cross checked with other staff who were present at the incident and our interpretations were presented back to them. 
The Fire Service under investigation employs approximately 2300 fire fighters and 400 support staff. The Service has 123 operational watches. The average age of a fire fighter is 42 and it is common for watch members to have worked together for 15-20 years. As fire fighters rely on each other for their personal safety, and because the organization is structured around watches, a strong notion of 'family' results. Members of 18 watches participated in focus group discussions. Each participating watch consisted of 8-15 male fire officers. The sessions lasted between 3 and 5 hours, 15 out of the 18 sessions were recorded and the collected data amounted to over 100 hours of transcribed discussion. The sessions were conducted using a form of CATWOE analysis as a research instrument (Checkland, 1981). CATWOE is part of the Soft Systems Methodology as is a technique for analysing activity within organizations from various perspectives Customers, Actors, the Transformation of inputs to outputs, the World View or rationale that makes the Transformation meaningful, the Owners of the Transformation process and the external Environmental constraints. To begin, a typical, non-information technology related scenario was presented to the group and the Customers, Actors, the various Transformation processes and World Views, the possible Owners and range of Environmental constraints were discussed collectively. When the watch were familiar with the use of CATWOE they were split into small groups and asked to identify a scenario where they felt additional knowledge or technology may have helped or where information technology was part of the scenario. These were converted into case vignettes with supporting graphical CATWOEs for presentation to management and other groups for further input and reflection. Of 102 resultant vignettes, 58 included elements of mobile technology use. From this data, three cases are presented which illustrate the changing dynamics between primary and secondary users resulting from the 
introduction of mobile technologies into the given scenarios. In each of the cases, the names of the fire personnel have been made anonymous.

\section{The Case Study: Mobile Computing in a UK Regional Fire Service}

\section{Scenario 1: Traffic Flow Modelling at Incidents}

The Fire Service was called to a city centre incident where gas cylinders had overheated and were in danger of exploding. According to procedure, a 200m exclusion zone was made around the cylinders. This resulted in transport disruption and a large car park being cordoned off. When creating exclusion zones the geographically remote Command and Control office ('Control') usually use a traffic flow modelling application to determine which roads to close and relay their decision to the incident ground. At fire incidents the Fire Service direct road closures and other emergency services such as the Police Service operate in a supporting role. This approach caused conflict between emergency services’ personnel and lacked context specific knowledge as no one at the incident was involved in the decision making process. Therefore, mobile technologies were implemented to facilitate the transfer of the road closure decision to the incident ground so that decisions could be taken in situ and collaboratively with other emergency services. A traffic flow modelling application run on a laptop linked to a plasma screen was used. Senior, 'at incident' fire fighters' views were largely positive, as one stated:

'we can relay to all fire fighters visually what is going on, we can download projected traffic flows to determine, in collaboration with the road traffic police, which roads can viably be opened to maintaining traffic flow and can, on site, model a variety of scenarios regarding the effects of closing roads' - James, area commander

In this case, the primary user group had changed from Control to a wider, inter-organizational primary user group based at the incident ground. Control assumed an observational, secondary user role. Yet, half an hour after reaching a road closure decision, incident ground personnel 
were contacted by Control and 'advised' to open certain roads. It emerged that Control had been using the same modelling application to generate alternative models. Fire Service incident management procedures are clear and dictate that the management of an incident resides with the most senior fire fighter (or their nominee) who is present at the incident. However, when the mobile technology empowered incident ground personnel's decisions resulted in an outcome that was not agreeable to Control, who had been relegated to the status of secondary user, Control effectively reassumed the role of primary user.

The other intended secondary user group were the operational fire fighters who were expected to implement the installation of exclusion zones based upon information provided by senior fire personnel derived from the traffic flow application. By transferring the decision making to the incident ground, groups of senior personnel from the various emergency services congregated around the technology whilst they generated alternative road closure scenarios. The presence of the technologies thus changed senior personnel's role at the incident and this was noticed by the operational fire fighters. John, a fire fighter stated:

'I think it makes us look like jerks, it's not about screens and stuff it's about doing something' - John, fire fighter

And another was quick to add:

'they keep putting different maps up, you think you know what they want but then another model goes up, we just stopped looking at it and waited for Officer Adam to eventually tell us what to do'- Alex, fire fighter

As with John and Alex's comments, many other operational fire fighters reported that they felt more distant from the incident based senior officers and perceived that they were focusing 
attention on the technology which was interfering with their managers' 'proper job' of dealing with the incident in a 'hands on' way. As another added:

'I don't see that it gives us any answers, Officer Chadwick spent all his time fiddling with the computer' - Evan, fire fighter

\section{Scenario 2: The GPS Trial}

The Service had been trialling a Global Positioning System (GPS) in fire engines which produces a provisional route to an incident, dynamically adapts to deviations from its initial route and relays information regarding current location back to Control. The intended primary user was the fire fighter responsible for providing navigation instructions to the driver, the secondary user. Several drivers discussed the stress that the overload of information supplied by the GPS caused. Specifically, when directions were supplied by the navigator there is a tacit understanding, based on possibly years of working together, regarding when directions may be required. Indeed, when we asked how the GPS was helping, one fire fighter said:

'the GPS systems are fine but to be honest we know where we are going anyway' Carlos, fire fighter.

And Gary, a colleague, continued:

We've decided to ignore it - I mean it gives you the right info, but it makes you question whether your making the right decision and we can't afford that when we're going at 50 [MPH] down some street'

With the GPS in place, it became apparent that navigators were supplying significantly more information which was regarded as superfluous. Additionally, we discovered that the GPS was monitored by Control, who had previously relied on radio feedback from the fire fighters. Although formally the Officer in Charge is the one at the incident, examples emerged where the GPS disempowered the incident based officers: 
'Well it means Control knows where we are which is fine - but I had earache from them the other week about me ignoring it - but you can't take a pump down Tenby St - it's too narrow, it was quicker to go via Castle View, but Control gave me a right mouthful' Frank, driver

And:

'we've got this system where you have to let Control know when you've arrived at an incident, we get there then give it a few minutes to suss out [assess] the situation before telling Control we were there. Now they know we're there and are straight on our case to report back' - Simon, fire fighter

The GPS has subsequently been largely abandoned by drivers and navigators. Numerous incidents of deliberate sabotage of the GPS handsets were reported in the focus groups which effectively removed the sets from the fire engines. Other fire fighters reported some compliance by switching the handset on but then placing it securely out of the way and not referred to:

'right now Steve sticks it in the torch holder and sticks the torch in his top pocket there's a bit of a cheer when he gets rid of it' - Gary, fire fighter

\section{Scenario 3: The Hazardous Chemicals Incident}

Historically, fire fighters dealing with chemical incidents relied on a hazardous chemicals manual, an assessment of the incident at hand, accumulated experiential knowledge and backup support from remote hazardous chemicals experts. At this incident the fire fighters attended a fire at a chemical company, equipped with a laptop which ran a hazardous chemical procedures application. The chemical company's chief chemical engineer explained that the fire was in a secure chamber and that the chemical was in no immediate danger of overheating. It was the corrugated paper in an outer chamber that was on fire, which was easily accessible and could be extinguished with water.

Again, the introduction of mobile technologies at the incident changed user relations. It became apparent that once the hazardous chemicals application was initiated the fire fighters felt 
compelled to follow the embedded scripts because they perceived the technology to be 'right'.

The technology also gave onlookers the perception that they were unable to make an independent analysis of the situation:

'the chemist was going mad, he just kept saying 'are you going to believe me or that $\mathrm{f}^{* * * * *} \mathrm{~g}$ computer, of course the stuffs hazardous but it's not on fire ... but it will be if you don't shift"' - Ben, fire fighter

In this case, the fire fighters deferred to the technology, even when it was clear that the application was 'context poor' they referred the matter to Control and assumed the role of a secondary user. Those at Control became primary users and directed the management of the incident, without being fully aware of the context. This resulted in an overcompensation strategy as related to the amount of effort and level of danger associated with the issue at hand. Those at the incident were told to wait for further advice, the arrival of breathing apparatus, decontamination units and a specific type of extinguishent. An unintended outcome of this, we were told, was unexpected public interference:

'So I phone Control and start explaining the situation to them and the chemist is shouting at me to listen to him, not the laptop. He was getting really $\mathrm{p}^{* * * *} \mathrm{~d}$ off that I was talking on the phone and to be honest he was right, I mean they're [Control] not there are they, and all they could see was the same file as I could see on the laptop and that didn't mention anything about corrugated paper stuff round the flask being on fire' Grahame, officer in charge

After 20 minutes, the chemical engineer lost his patience, went into the building and put the fire out.

\section{Discussion}

Primary and secondary user roles have existed since the start of the information technology era (Eason, 1988, Friedman and Cornford, 1989). However, we suggest that the deployment of mobile technologies can change the relationships between primary and secondary users which 
may ultimately affect the success of mobile technologies 'in the field. The deployment of mobile technologies implies a move towards perpetual contact both with the technology itself and with a remote coordinating or monitoring authority (Lyytinen et al., 2004, Katz and Aakhus, 2002). With such a move towards perpetual contact, mobile technologies become an intervention device which aims to provide support or information to geographically distanced users, by bringing them and their physical and virtual worlds of interaction closer together (Lee and Liebenau, 2002, Castells, 1996). However, this study suggests that the notion of perpetual contact may influence who adopts primary and secondary user roles (whether officially or not) and how control is asserted over those roles through deployed mobile devices. Furthermore, whilst valid concerns regarding information overload as a result of mobile technology deployment have been raised (Ljungberg and Sorensen, 2000) this study also suggests that simply the presence of information delivered via mobile technologies can affect primary and secondary user relations in various ways. We shall discuss these issues further now.

Perpetual Contact: Within the case study, contact with the technology tended to widen the distance between primary and secondary users. In the traffic flow modelling scenario the operational fire fighters, who were secondary users, perceived that the technology was taking the senior fire fighters' attention away from the incident. Previously senior officers concentrated on physical actions concerning deployment of personnel across the incident. The mobile technology transferred their attention to the iterative modelling of virtual deployments. Operational fire fighters perceived this as disengagement from the physical environment and reported uncertainty regarding the actions they were supposed to be taking. Similarly, at the chemical incident the chief chemist perceived that the Fire Service were inactive and were engaging with the 
technology rather than the situation. The interesting issue here is that although we might consider the chief chemist as an unintended secondary user of the output of the system that is the fire service, he was not a-priori specified intended secondary user of the mobile technology. Indeed, he is more appropriately thought of as a 'bystander' who, because of the presence of a mobile technology, becomes engaged as a result of other users’ behaviour.

Deferring to Technology: In certain scenarios, the presentation of information via what appeared to be advanced technologies resulted in the primary users deferring to the technology, rather than using their judgement. Their decision making was inhibited rather than enabled. For example, the fire fighters use of the chemical hazard procedures database and the navigators' 'over informing' of navigational instructions provided by the GPS. In both cases the fire fighters interacting with the mobile technologies were experienced officers and, theoretically, capable of contextualising (as in the case of the chemical incident) or filtering (as in the case of the GPS) the information provided by the mobile technologies. However, they experienced difficulty in juggling between the virtual and situated spaces of interaction (Bunzel, 2002). Instead they chose to defer to the technology rather than use it to make decisions, effectively relinquishing their primary user role. Yet, with the GPS such deferral was ultimately questioned by the users and the technology was abandoned. As illustrated in these incidents, the use of mobile technologies does not guarantee that secondary or primary users will be comfortable with the roles assigned to them, even if they held those roles before the technology was deployed.

Supervision and Control: The regimented style of the Fire Service coupled with the high degree of improvisation and uncertainty, and the geographically dispersed nature of the work 
suggests that deploying mobile technologies to support supervision, coordination and control of fire fighters would be welcomed by Fire Service personnel. However, as with prior studies, we show that the use of mobile technologies to support supervision and control may be contentious (Heath and Luff, 2000, Kallinikos, 2004). For example, the mobilisation of the traffic flow modelling application allowed a wider, inter-organizational, primary user group to be involved in the decision making process and more context rich information to be considered. However, whilst the new primary user group were positive about the deployment, the relegated primary user group, Control, were dissatisfied. In subsequent interviews with Control staff, they declared that the rationale for covertly generating alternative models had been simply 'because they could' and only chose to reassume their primary user status when they perceived that the incident based personnel were making 'incorrect decisions'. The incident based personnel disagreed with this view and indeed, the imposed alternative model appeared to be largely similar to the model generated at the incident. Also, with respect to route planning, the introduction of the GPS allowed Control to more closely monitor the fire engines whilst they were in transit and subsequently question routes taken to incidents. Control effectively operated as primary users using GPS feedback to maintain a real time view of fire engines' locations. The technology also allowed the specific role that Control assumed to change, the technology allowed them to increase the surveillance of the travel to, and arrival at incidents. Here 'dual' primary users found themselves in conflict, effectively Control, although being geographically remote, exerted more influence on the incident whilst the navigators and drivers were disempowered. Specifically a dichotomy appears to exist between relinquishing a primary user role or assume 'dual' primary user status whilst still maintaining some supervisory responsibility. 
Prior to the introduction of mobile technologies in such uncertain and dynamic situations the roles of primary and secondary user were clear and relatively static. However, our data suggests that mobile technologies may facilitate a more dynamic relationship between primary and secondary users, even allowing users to swap roles. In our cases the aim of providing richer information at, or on the way to, the incident ground has been achieved, yet this deployment has shown that expected primary users may be reluctant to assume their primary user role, that previous primary users may be reluctant to relinquish their role and that the technology enables the roles to be passed between individuals rather than embraced. Furthermore, the technology was intended to bridge the gap between different groups of primary and secondary users, yet there are examples of it disrupting previously harmonised user relations. Therefore, we suggest that existing secondary users should be fully considered before mobile technologies are introduced into a new scenario. This is important for two reasons as firstly, secondary users may become primary users when the deployment of the mobile technology occurs and secondly, existing secondary users may be affected where their relations with primary users will now be mediated by technology.

\section{Conclusion}

This study has considered the potential effects of mobile technologies on end user relations with a focus on the 'secondary user', those who are not intended to interact directly with the technology but are intended consumers of the technology's output. Our findings suggest that secondary users, an underrepresented group in information systems projects, are an important user group. Primary and secondary users existed prior to the deployment of mobile technologies in the Fire Service. We show how these roles have been altered and some of the implications that ensue from the altered user group dynamics. Within our study, there were benefits of 
deploying the technologies - the traffic flow application assisted collaboration amongst emergency services personnel for example. But we also surfaced a range of issues that need consideration. These include the need to acknowledge the role of mobile technologies in generating issues associated with perpetual contact, perceptions of technological capability, implications for user roles and supervision and control issues. These are all areas that require further investigation. The next development in this study is to further unpack the secondary user group by considering the role of 'bystanders' such as the chief chemical engineer and other members of the general public.

\section{Acknowledgements}

We would like to express our gratitude to the two anonymous reviewers and the editors Hans van der Heijden and Iris Junglas for their excellent advice on how to improve the paper. Thanks also to the fire fighters who shared their experiences with us.

Bunzel, D. (2002), "The rhythm of the organization: simultaneity, identitiy and discipline in an Australian coastal hotel", in Whipp, R., Adam, B. and Sabelis, I. (Eds), Making time: Time and management in modern organizations, Oxford University Press, Oxford, pp. 168-181.

Castells, M. (1996), The Rise of the Network Society, Blackwell, Oxford.

Checkland, P. (1981), Systems Thinking, Systems Practice, John Wiley \& Sons, London.

Checkland, P. and Holwell, S. (1997), Information, Systems and Information Systems - making sense of the field, John Wiley \& Sons, London.

Cooper, G. (2002), "The Mutable Mobile: Social Theory in the Wireless World", in Brown, B. and Green, N. (Eds), Wireless World: Social and Interactional Aspects of the Mobile Age, Springer, London, pp. 19-31.

Dahlbom, B. and Ljungberg, F. (1998), "Mobile Informatics", Scandinavian Journal of Information Systems, 10(1\&2), pp. 227-234.

Eason, K. (1988), Information Technology and Organisational Change, Taylor \& Francis, London.

Fitzgerald, B., Russo, N. L. and Stolterman, E. (2002), Information Systems Development: Method in Action, McGraw Hill Companies, London.

Flynn, D. (1998), Information Systems Requirements: Determination and Analysis, The McGraw-Hill Companies, London. 
Flynn, D. and Davarpanah Jazi, M. (1998), "Constructing User Requirements: A Social Process for a Social Context", Information Systems Journal, 8(1), pp.53-83.

Friedman, A. L. and Cornford, D. S. (1989), Computer Systems Development: History, Organization and Implementation, John Wiley and Sons, Chichester.

Gabriel, Y. (2000), Storytelling in Organizations: Facts, Fictions, and Fantasies, Oxford University Press, Oxford.

Heath, C. and Luff, P. (2000), Technology in Action, Cambridge University Press, Cambridge.

Hosein, I. and Whitley, E. A. (2002), "The regulation of electronic commerce: learning from the UK's RIP act", Journal of Strategic Information Systems, 11(1), pp. 31-58.

Kallinikos, J. (2004), "Farewell to Constructivism: Technology and Context-embedded Action", in Avgerou, C., Ciborra, C. U. and Land, F. (Eds), The Social Study of Information and Communication Technology: Innovation, Actors and Contexts, Oxford University Press, Oxford.

Katz, J. E. and Aakhus, M. (Eds) (2002), Perpetual Contact,Cambridge University Press, Cambridge.

Kristoffersen, S. and Ljungberg, F. (2000), "Mobile Informatics", in Braa, K., Sorensen, C. and Dahlbom, B. (Eds), Planet Internet, Studentlitteratur, Lund, pp. 137-157.

Laurier, E. (2001), "Why people say where they are during mobile phone calls", Environment and Planning D: Society and Space, pp. 485-504.

Lee, H. and Liebenau, J. (2002), "A New Time Discipline: Managing Virtual Work Environments", in Whipp, R., Adam, B. and Sabelis, I. (Eds), Making

Time: Time and Management in Modern Organizations, Oxford University Press, Oxford, pp. 126-139.

Ljungberg, F. and Sorensen, C. (2000), "Overload: From Transaction to Interaction", in Braa, K., Sorensen, C. and Dahlbom, B. (Eds), Planet Internet, Studentlitteratur, Lund, Sweden, pp. 113-36.

Luff, P. and Heath, C. (1998), "Mobility in Collaboration", in Poltrock, S. and Grudin, J. (Eds), Proceedings of the ACM conference on Computer-supported cooperative work ACM Press: Seattle, WA, pp. 305-314.

Lyytinen, K., Varshney, U., Ackermann, M. S., Davis, G., Avital, M., Robey, D., Sawyer, S. and Sorensen, C. (2004), "Surfing the Next Wave: Design and Implementation Challenges of Ubiquitous Computing Environments", Communications of the Association for Information Systems, 13(40), pp.697-716.

Miles, M. B. and Huberman, A. M. (1994), Qualitative Data Analysis: An Expanded Sourcebook, 2nd edn., Sage Publications Inc, Thousand Oaks.

Myers, M., D. (1997), "Interpretive Research in Information Systems", in Mingers, J. and Stowell, F. (Eds), Information Systems: An Emerging Discipline, The McGraw Hill Companies, London, pp. 239-266.

Pouloudi, A. and Whitley, E. A. (1997), "Stakeholder Identification in Inter-organizational Systems: Gaining Insights for Drug Use Management Systems", European Journal of Information Systems, 6(1), pp. 1-15.

Sharp, H., Finkelstein, A. and Galal, G. (1999), "Stakeholder Identification in the Requirements Engineering Process", in Workshop on Requirements Engineering Processes (REP'99) at DEXA'99 Florence, Italy, pp. 387-391.

Snowden, D. (2002), "Narrative Patterns: Uses of Story in the Third Age of Knowledge Management", Journal of Information and Knowledge Management, 1(1), pp. 1-5. 
Walsham, G. (1995), "Interpretive Case Studies in IS Research: Nature and Method", European Journal of Information Systems, 4(2), pp. 74-81.

Weilenmann, A. and Larsson, C. (2002), "Local use and sharing of mobile phones", in Brown, B., Green, N. and Harper, R. (Eds), Wireless world: Social and interactional aspects of the mobile age, Springer-Verlag, London, pp. 92-107.

Yin, R. (1994), Case Study Research: Design and Methods, 2nd edn., Sage Publications, London. 